\title{
A Detailed Rubric for Assessing the Quality of Teacher Resource Apps
}

\author{
Todd Cherner \\ Portland State University, \\ Portland, Oregon, USA \\ chernert@pdx.edu
}

\author{
Alex Fegely \\ Coastal Carolina University, \\ Conway, South Carolina, USA \\ agfegely@coastal.edu
}

\author{
Cheng-Yuan Lee \\ Coastal Carolina University, \\ Conway, South Carolina, USA \\ clee@coastal.edu \\ Lauren Santaniello \\ Indian Hills High School, \\ Oakland, New Jersey, USA \\ Isantaniello@rih.org
}

\begin{abstract}
Since the advent of the iPhone and rise of mobile technologies, educational apps represent one of the fastest growing markets, and both the mobile technology and educational app markets are predicted to continue experiencing growth into the foreseeable future. The irony, however, is that even with a booming market for educational apps, very little research regarding the quality of them has been conducted. Though some instruments have been developed to evaluate apps geared towards student learning, no such instrument has been created for teacher resource apps, which are designed to assist teachers in completing common tasks (e.g., taking attendance, communicating with parents, monitoring student learning and behavior, etc.). Moreover, when teachers visit the App Store or Google Play to learn about apps, the only ratings provided to them are generic, five-point evaluations, which do not provide qualifiers that explain why an app earned three, two, or five points. To address that gap, previously conducted research related to designing instructional technologies coupled with best practices for supporting teachers were first identified. That information was then used to construct a comprehensive rubric for assessing teacher resource apps. In this article, a discussion that explains the need for such a rubric is offered before describing the process used to create it. The article then presents the rubric and discusses its different components and potential limitations and concludes with suggestions for future research based on the rubric.
\end{abstract}

Material published as part of this publication, either on-line or in print, is copyrighted by the Informing Science Institute. Permission to make digital or paper copy of part or all of these works for personal or classroom use is granted without fee provided that the copies are not made or distributed for profit or commercial advantage AND that copies 1) bear this notice in full and 2) give the full citation on the first page. It is permissible to abstract these works so long as credit is given. To copy in all other cases or to republish or to post on a server or to redistribute to lists requires specific permission and payment of a fee. Contact Publisher@InformingScience.org to request redistribution permission.
Keywords: Instructional Technology, Teacher Resources, Educational Apps, and Tablets

\section{Introduction}

The rise of wireless technologies has paved the way for digital, paperless classrooms to become the new norm in education (Barseghian, 2011; Hofstein et al., 2013; Hu, 2009). Schools and districts are emphasizing this transition 
as they purchase laptops and tablet devices for all their students and teachers, so instruction that blends face-to-face instruction with digital tools can be implemented (Morgan, 2014; Richardson et al., 2013). Part and parcel with this transition, however, is that teachers are not only using instructional technologies, but they are also using technologies that help them complete common, daily tasks. Examples of these tasks include keeping, maintaining, and using grade books, attendance logs, and assessments among other materials. In addition, teachers will need to store confidential information in secure storage areas, both on and offline, and be able to communicate with parents, colleagues, and other stakeholders digitally. Currently, an abundance of these technologies have been developed as apps that run on tablet devices and personal computers, but they have largely gone unanalyzed. It is the purpose of this article to put forward a comprehensive instrument designed specifically to analyze the quality of apps designed to support teachers as they complete routine tasks. To do so, a review of current rubrics designed specifically for educational apps will be presented. Based on that work, the researchers will explain how they developed a rubric designed to analyze "teacher resource" apps, which is a term they adopted from Cherner, Dix, and Lee (2014) to describe apps created specifically to support teachers as they complete routine tasks. As the transition to paperless classrooms continues, this rubric will help teachers analyze the strengths and weaknesses of teacher resource apps that are available to them.

\section{Identifying Current App Evaluation Rubrics}

Since apps have existed, the rating systems used to evaluate their quality have gained increased attention. The App Store and Google Play, two giants in the distribution of apps, have used fivepoint systems to evaluate the quality of apps. These systems allow users to score an app as one, two, three, four, or five stars and leave a comment. The shortcoming with these systems is specific criteria to differentiate an app that scores a "three" versus one that scores a "four" or "two" are not easily made. Why an app might score a "two" to one person may well be the reason another person scored it as a "three" or higher, which complicates the type of information that can be learned from the ratings. In this regard, the validity and reliability of apps' quality using the App Store and Google Play's generic five-point scoring systems are questionable (McIlroy, Ali, Khalid, \& Hassan, 2015). Educational researchers have keyed on these concerns and responded by putting forward a variety of rubrics.

Walker (2011) produced one of the first rubrics created for evaluating apps, and it consisted of six dimensions: Authenticity, Curriculum Connections, Differentiation, Feedback, Motivation, and User Friendliness. Walker's rubric was created to analyze all types of educational apps. Buckler (2012) also developed a rubric to evaluate apps. In his rubric, he used the dimensions of benefits, cost, ease of use, adjustability, feedback, and application to assess the quality of apps for students with special needs. Lee and Cherner (2015) then analyzed the quality of both Walker and Buckler's rubrics, and they found shortcomings that included:

- Both rubrics use a four-point evaluation system that does not align with quality rubrics that use a five-point system (Jamieson, 2004); and,

- The limited amount of dimensions used by the rubrics does not enable comprehensive evaluations to be made.

Outside of these preliminary rubrics, Balefire Labs (2013) put forward an evaluative checklist that uses the following 12 dimensions: Feedback for Correct Response, Error Feedback, Adapting Difficulty, Error Remediation, Mastery-Based Instruction, Frequent and Meaningful Interaction, Clearly Stated Learning Outcomes, Relevant Screen and Sound Use, Learner Support Available, Easy-to-Use Interface, Age-Appropriate Reading Level, and Performance Reports. Though the terms on their checklist are operationalized, they are not aligned to specific research. Additionally, the checklist is limited in that specific criteria needed to receive a "Yes" or "No" rating is not articulated. This is problematic because if an app provides only generic feedback regarding the 
accuracy of an answer opposed to one that provides detailed information, the checklist has no way to differentiate the quality of the feedback. Rather, it can only affirm that feedback is offered. In response, Lee and Cherner (2015) put forward a comprehensive rubric that built on published research used to evaluate educational software and websites and modified it so it was appropriate for analyzing educational apps.

The rubric Lee and Cherner (2015) put forward uses 24 different dimensions that are grouped into three domains: Instructional Value, Quality of Design, and Potential to Engage Students. Each domain uses separate dimensions to assess apps, and each dimension is evaluated using a fivepoint Likert scale. Furthermore, the domains, dimensions, and descriptors used to evaluate if the app scored a one, two, three, four, or five are operationalized. As Lee and Cherner (2015) explained, they developed the rubric so the criteria used to evaluate apps are clear and comprehensive. The rubric put forward in this article presents an evaluation instrument that is modeled after Lee and Cherner's (2015) rubric. However, because their rubric was designed to assess instructional apps, this rubric is original in that it was developed to assess teacher resource apps.

\section{Creating an Evaluation Rubric for Teacher Resource Apps}

To ensure that an evaluation instrument was needed for teacher resource apps, a thorough review of existing rubrics was conducted. To investigate if a rubric of this variety existed, both the Google Scholar and Education Resource Information Center databases were searched. The search used combinations of the following key terms: rubric, app, teacher resource, grade book, attendance log, communication, and student behavior. Although several hundred articles were reported, none of them contained rubrics designed to evaluate teacher resource apps. The researchers then turned to the Google Search Engine to investigate if any such rubrics existed on the Internet. This search was conducted because the researchers postulated a rubric created by a practitioner for these purposes was more likely to be found using the Google Search Engine than in a database of research articles. After conducting their search, the researches located multiple rubrics and checklists; however, they were all designed to evaluate instructional apps. As a result, the researchers decided it was prudent to begin developing a rubric specifically for evaluating teacher resource apps.

To organize the rubric, Table 1 was first developed with the purpose of matching the potential rubric dimensions with relevant literature and the subsequent framework the literature identified as being meaningful.

With Table 1 in place, the researchers created categories to describe the dimensions they found. These categories were formalized into the rubric's three domains that came to include: (A) Efficiency, (B) Functionality, and (C) Design. The researchers reviewed the different dimensions and coded them to a specific domain (Coffey \& Atkinson, 1996). To ensure each dimension was operationalized, Table 2 presents the format the researchers used to frame each dimension into a question and offer responses in the form of indicators $1,2,3,4$, and 5. 
Table 1: Alignment of theoretical frameworks and relevant literature to rubric dimensions

THEORETICAL FRAMEWORK

Development guide for mobile apps

\begin{tabular}{|l|}
\hline Human interactive design \\
\hline Multimedia learning principles \\
\hline
\end{tabular}

Productivity improvement

Ssability design

\section{RELEVANT LITERATURE}

Bouard, Schanda, Herrscher, \& Eckert, 2013; Hsu, Ching, \& Grabowski, 2014; Parsons, n.d.; Zhu, Xiong, Ge, \& Chen, 2014

Bloch, 1995; Ha, Yoon, \& Choi, 2007; Lee \& Cherner, 2015; Liao et al., 2011; Mayer, 2001; Mayer \& Anderson, 1991, 1992; Reeves \& Harmon, 1993; Tractinsky, Katz, \& Ikar, 2000; Van der Heijden, 2003

Hong, Thong, \& Tam, 2004; Mayer \& Moreno, 2003; Mergel, 1998;

Weinschenk, 2011; Zhang, 2000

Cherner, Dix, \& Lee, 2014; Heide \& Henerson, 2001; Litayem, Dhupia, \& Rubab, 2015; Tomlinson, 1999; Wasniewski, 2013

Coughlan \& Morar, 2008; Elissavet \& Economides, 2003; Garrett, 2010; Helander, Landauer, \& Prabhu 2014; Kennedy, Petrovic, \& Keppell, 1998; Lee \& Cherner, 2015; Olson \& Olson, 1990; Reeves \& Harmon, 1993; Schibeci, et al., 2008; Shiratuddin \& Landoni, 2002

\section{RUBRIC DIMENSIONS}

A3. Guidance

B2. Collaboration \& Communication

B3. Ability to Save Progress

B5. Platform Integration

B6. Security

C1. Navigation

C4. Aesthetics

C7. Media Integration

C6. Information Presentation C8. Free of Distractors

A1. Productivity

A2. Frequency

A4. Relevance

A5. Credibility

A6. Differentiation

B1. Multipurpose

B4. Modification

C2. Ease of Use

C3. Customization

C5. Screen Design

\section{Table 2: Example Rubric Dimension}

A2. Frequency: How often will teachers utilize this app?

5

Teachers could use this app daily
4

Teachers could use this app weekly
3

Teachers could use this app monthly 2

Teachers could use this app once a semester
1

N/A

Teachers could Not Applicable use this app one time and not return to it

In Table 2, it shows the Efficiency domain's Frequency dimension, which uses the question to operationalize the dimension. Evaluators respond to the question by choosing the indicator that best aligns to it. If none of the indicators align to the question, evaluators are to choose N/A. With a draft of the rubric in place, the researchers used the rubric to evaluate 10 sample teacher re- 
source apps. As they used the rubric, they polished wording to ensure clarity and usability before member checking (Carlson, 2010).

When member checking, the researchers sought to confirm the language they used in the rubric was understandable and logical (Krefting, 1991). To member check, the researchers chose three individuals who had quality experience with rubrics. The first individual was a veteran special education teacher who taught at the elementary level. This individual held a graduate degree in Literacy Education and used apps frequently as part of her routine teaching duties. The two other member checkers held doctoral degrees and had expertise in quantitative research methods, assessment instruments, and pedagogy. To guide this process, the researcher had all the member checkers assess the rubric by evaluating three sample apps with it, and then use the Rubric Review Form (Appendix B) to capture their experience doing so. Each member checker completed their evaluations and returned the Rubric Review Form to the researchers. The researchers then met and discussed the comments they received and modified the rubric accordingly. The researchers then repeated the process. In response, the member checkers all confirmed that the changes made were appropriate and agreed they were comfortable using the rubric. At this point, the rubric was formalized.

In the next section, the different domains and their subsequent dimensions are discussed in detail, and the complete teacher resource rubric is located in Appendix A. To ensure readers comprehend the rubric's design and organization, they are encouraged to refer back to the framework provided in Table 1 and complete rubric shown in Appendix A.

\section{Domain A: Efficiency}

The Efficiency domain analyzes if an app has the potential to increase the speed, competence, and ability of teachers to complete daily tasks. To do so, six dimensions are used to evaluate an app's efficiency that include (A1) Productivity, (A2) Frequency, (A3) Guidance, (A4) Relevance, (A5) Credibility, and (A6) Differentiation.

\section{A1. Productivity}

The "Productivity" dimension measures an app's potential to increase teachers' effectiveness in their daily routine tasks. For teachers, productivity is one of the major concerns in the digital classrooms (Heide \& Henerson, 2001). To be effective, teachers need to know how to tackle routine tasks efficiently as part of their routines, which may include lesson planning, classroom management, grading, student performance evaluation, and all other administrative tasks. A quality teacher-resource app assists teachers in being as efficient as possible in handling all these types of tasks.

Example App for Productivity. Apps that streamline teachers' workflow and add efficiency to their duties score well in this dimension. For example, Socrative Teacher increases teachers' productivity when formatively assessing their students. Using this app, teachers can create or import an assessment and quickly send it directly to their students' tablets. Students then complete the assessment, and the app analyzes the data and presents it as a detailed report. The report analyzes student achievement levels and shows which concepts to review, considerations for grouping students based on assessment data, and content for re-teaching. Because Socrative Teacher increases teachers' productivity for grading and analyzing student achievement, it earns a high score for this dimension.

\section{A2. Frequency}

The "Frequency" dimension examines how often teachers may utilize an app. Given the difference in the purposes of the apps, the usage frequency of apps varies greatly. Apps with potential 
to be used by teachers daily possess higher value than those that are used occasionally. For instance, a classroom management app is utilized more frequently than an app designed for writing individual education plans (Wasniewski, 2013). This dimension analyzes frequency because an app used often is more valuable than one which is seldom used.

Example App for Frequency. Apps that teachers will use multiple times a day score highest in this dimension. ClassDojo, a classroom management app, has the potential to be used often during a class period to record anecdotal evidence of students' participation, behavior, and attendance. In addition, ClassDojo's random student selector is a peripheral function that has implications for increasing its usage in the classroom. Because of its multiple classroom applications, ClassDojo scores well in this dimension due to teachers being able to use it daily.

\section{A3. Guidance}

The "Guidance" dimension examines if an app provides sufficient support to assist teachers when using it. Guidance can be in the forms of tutorials, help desk, tips, and labeled diagrams, which provides roadmaps for navigating the apps and understanding its functionality. Because mobile devices are equipped with hardware required to run sophisticated apps, newer versions are often packed with complex features that take advantage of recent advances in tablet technologies (Bouard et al., 2013). This trend allows apps to include complicated interfaces that may result in users becoming lost when interacting with them. As the result, it is suggested that a corresponding guidance system should be added to accompany the new features added to an app (Parsons, 2015). Without appropriate guidance, teachers risk becoming lost while using apps and become confused and frustrated.

Example App for Guidance. Apps that provide hints, step-by-step instructions, and tutorials score well in this dimension. When teachers open Additio, the app first explains each of its core functionalities with a scroll-through text and a picture overlay that labels each buttons' functionalities. As teachers use Additio, the app highlights individual buttons, displays a description of their function, and blacks out the rest of the screen so teachers are able to focus directly on the button without becoming distracted. In addition, Additio includes a Help button that teachers can use to access commonly asked questions and answers, text instructions, and video tutorials. Due to the support Additio provides teachers, it scores a 5 in this dimension.

\section{A4. Relevance}

The "Relevance" dimension gauges how useful an app can be to teachers of all grade levels and disciplines. Unlike instructional apps that can be designed for specific content areas or age groups, teacher resource apps should be able to support all teachers as they complete common tasks (Cherner et al., 2014). Examples of these tasks include maintaining a safe learning environment and communicating with parents, colleagues, students, and supervisors. When assessing the relevance of teacher resource apps, it is imperative that evaluators see the commonalities between the tasks that teachers across grade levels and subject areas must complete in order to prepare for, provide, maintain, and analyze the instruction given to students.

Example App for Relevance. Apps that can be used in any classroom and subject score highest in this dimension, and Classroom Noise Manager exemplifies these traits. With it, teachers are able to track their classroom's sound level with a needle gauge display. As the noise level in the classroom rises, the needle climbs. As the noise level in the classroom decreases, the needle lowers. Classroom Noise Monitor scores a 5 in Relevance because all teachers, regardless of subject area or grade level, can use this app as a classroom management tool. 


\section{A5. Credibility}

The "Credibility" dimension examines if an app's content is validated by a reputable source (e.g., endorsed by professional organizations, government agencies, educational laboratories, or supported by research). When an app presents factual content and is used by teachers for building lesson plans or sharing information with students, particular attention needs to be paid to the legitimacy of the content. When an app is made available through the iTunes store or Google Play, its content is not highly scrutinized or validated by a reputable source (Jiang, Ma, Ren, Zhang, \& $\mathrm{Li}, 2014)$. In fact, often times the content is not verified at all by app publishers. It is the responsibility of teachers to examine an app's content. Therefore, this dimension gives value to apps that are endorsed or credentialed by a reputable body or organization.

Example App for Credibility. Apps that have ties to established, reputable agencies and companies score highly in this field. For example, The Heinemann Teacher Tip app provides educators with daily tips about writing, reading, and general literacy instruction. The Heinemann Teacher Tip app is distributed by Heinemann, an industry leader in professional development resources for educators. Because this app is associated with Heinemann and its partnership with Houghton Mifflin Harcourt, another industry leader, this app earns a high score in Credibility.

\section{A6. Differentiation}

The "Differentiation" dimension evaluates if an app has the potential to engage diverse students. As they come to school with various learning styles, linguistic abilities, cultural backgrounds, and much more (Tomlinson, 1999), students need skilled teachers who are able to modify instruction to meet their needs (Kameenui \& Carnine, 1998). If apps are to be used by teachers to engage all students, apps should ideally assist teachers in addressing their students' uniqueness and different needs.

Example App for Differentiation. Apps that recognize learners obtain information in nonstandardized ways score well in this dimension. For example, the Lesson Planning app contains a database of lesson plans teachers can browse by grade level and topic. Each lesson in contains detailed steps teachers can follow when implementing it in their classroom. To help ensure the lessons cater to the needs of diverse students, the app includes differentiated support and extension activities to engage all students, which provides for a high score in this dimension.

\section{Domain B: Functionality}

After examining an app's potential to increase productivity, the next consideration is its functionality. A high-quality app is developed so teachers can interact with it efficiently and smoothly while completing tasks. Lee and Cherner (2015) explained that teachers who are able to use an app intuitively are more likely to fully utilize all of its features, which adds value to its functionality score. To measure an app's functionality, the following dimensions are used: (B1) Multipurpose, (B2) Collaboration \& Communication, (B3) Ability to Save Progress, (B4) Modifications, (B5) Platform Integration, and (B6) Security.

\section{B1. Multipurpose}

The "Multipurpose" dimension evaluates an app's capability for performing common tasks (e.g., storing grades, recording student behavior, communicating to other stakeholders, creating lesson plans, and designing assessments). With advances in tablet technologies, app developers are able to take advantages of the devices' more powerful hardware and larger storage systems. These advances allow developers to design apps with more complex and sophisticated features to serve multiple needs (Litayem et al., 2015). An app with a high rating in this dimension has the ability to perform several of these types of tasks simultaneously. 
Example App for Multipurpose. Apps that have the capacity to perform multiple functions score the highest in this dimension, and Teacher.io exemplifies those characteristics. With it, teachers first create classes and then upload syllabi and schedules, post assignments, distribute tests, and share other resources with it. Once students join a class, they are able to access and engage all of its materials and assignments. Plus, Teacher.io lets teachers send students reminders and announcements. Due to its variety of functions, Teacher.io scores a 5 in Multipurpose.

\section{B2. Collaboration \& communication}

The "Collaboration \& Communication" dimension explores if an app provides teachers the opportunity to share ideas, resources, lesson plans, and strategies with other stakeholders. In a review of the theoretical based research studies, Hsu et al. (2014) found that enriched learning opportunities were observed in the adoption of Web 2.0 applications, such as blogs, wikis, collaborative documents and concept mapping, VoiceThread, video sharing applications (e.g., YouTube), microblogging (e.g., Twitter), social networking sites, and social bookmarking. Apps with a builtin capability for communication provide teachers an opportunity to collaborate with others and be part of a learning community.

Example App for Collaboration and Communication. Apps that allow teachers to collaborate score well on this dimension, and collaboration may include sharing of lesson plans, worksheets, activities, and other resources between teachers. Google Drive exemplifies these characteristics.

With it, teachers are able to view, edit, store, comment, and share documents with other teachers. (Teachers will need to connect other apps, such as Google Doc, Google Slide, and Google Sheets, to maximize their experience using Google Drive). With a robust collection of options to engage multiple stakeholders through collaboration and communication, Google Drive includes the essentials needed to score a 5 in this dimension.

\section{B3. Ability to save progress}

The "Ability to Save Progress" dimension explores if an app allows teachers to save their work before resuming it at a later point in time. Lee and Cherner (2015) emphasized that the ability to save work is vital for an app because when the use of app is interrupted and then resumed at a later time, teachers do not want to start from the beginning. Instead, they would rather resume working automatically from where they previously left off.

Example App for Ability to Save Progress. Apps that automatically save progress score the highest in this dimension. For example, TeacherKit allows users to touch and change grades, behavior, attendance, calendar, and roster information. These changes are automatically saved so if teachers accidentally close the app, get distracted, or lose power, there is no loss of progress and the work was saved. When the app is reopened, teachers can resume using it from the point where they left off. Because this app saves and restores work automatically, TeacherKit scores a 5 in this dimension.

\section{B4. Modification}

The "Modification" dimension analyzes if teachers are able to correct or modify data they inputted into the app. When entering grades, attendance, behavior, or other data into an app, teachers may make a mistake or may need to change the data they entered into the app. This dimension analyzes the ease in which teachers can adjust the data they entered into the app. To score well in this dimension, the app must automatically realize a mistake was made and correct it or allow teachers to adjust data stored in the app with minimal effort.

Example App for Modification. Apps that allow teachers to edit information stored in it easily score well in this dimension. For example, the Teacher App \& Grade Book allows teachers to 
update information related to attendance, notes, grades, classes, and students. This app's simple workflow requires few selections when modifying data. Teacher App \& Grade Book scores a 5 in this dimension due to its intuitiveness and ease with which the interface aids teachers in updating and modifying data.

\section{B5. Platform integration}

The "Platform Integration" dimension analyzes if an app connects its content to different platforms. The term Platform Integration refers to apps that have the capacity for sharing any artifacts or documents between the app and other apps, online communities, independent websites, and email (Lee \& Cherner, 2015). This relatively new dimension is important because being able to share learning artifacts and content across platforms adds accessibility to the artifacts created and knowledge gained. A high score in this dimension indicates the artifacts created in one platform can be easily shared.

Example App for Platform Integration. Apps that have the capacity to send information to other platforms score well in this dimension, and Nearpod exemplifies these characteristics. With Nearpod, teachers are able to create presentations that can be shared, opened, and utilized on either the tablet app or a desktop computer's web browser. To do so, teachers distribute a view code to students, and student input it into either the Nearpod app or website. Teachers can synchronously guide students through the presentation, regardless of the platform or operating system. Teachers can also share presentations made with Nearpod via email. With these functionalities, Nearpod is representative of a high-scoring app for this category.

\section{B6. Security}

The "Security" dimension analyzes if the data entered into the app is both confidential and safe. If an app is used to store student data (e.g., grades, contact information, or demographic information), ensuring the data stored is secure and is not accessible to unauthorized users is crucial (Zhu et al., 2014). A common method to secure the data stored in an app is to include an additional authorization procedure by requiring a passcode to execute an app. A high score in this dimension denotes that an app has a security system in place that is secure and the information stored in the app is not public or accessible to outsiders.

Example App for Security. Apps that are password protected and require teachers to sign in across various platforms score best in this dimension. ExitTicket stores formative student assessment data. To access the data, the app requires a sign-in with a teacher username and password on both the app and website, and teachers will be signed out after a period of inactivity. Because ExitTicket requires multiple sign-ins and requires teachers to re-enter their username and password after being idle, it includes the characteristics needed to score well for security.

\section{Domain C: Design}

If an app is ranked high for its productivity value and functionality but fails to provide a friendly interface, the value of the app decreases significantly. This domain analyzes the app's digital pathways, setup, and makeup to ensure teachers have a pleasant experience while engaging it. The dimensions used to evaluate these qualities include (C1) Navigation, (C2) Ease of Use, (C3) Customization, (C4) Aesthetics, (C5) Screen Design, (C6) Information Presentation, (C7) Media Integration, and (C8) Free of Distractors.

\section{C1. Navigation}

The "Navigation" dimension explores how easily teachers can move through an app's content and options. Orientation is the major aspect of navigation, meaning that teachers have an understand- 
ing of where they are in a computer program and the options presented to them regarding where they may go (Reeves \& Harmon, 1993). An app with a clear navigational structure in place supports teachers as they move through an app's content and options, allowing them to maintain their orientation in the app (Lee \& Cherner, 2015). Many apps achieve this goal by providing conventional visuals, such as breadcrumbs, navigational arrows, and a sitemap.

Example App for Navigation. Apps that have logical navigational options and structure score best in this dimension. Remind 101 has a clearly laid out sidebar menu, available from any screen, that allows teachers to choose a variety of options using clearly identified icons and text. Remind101 scores well in this dimension because of its very accessible sidebar menu, which highlights the tools and features available to teachers.

\section{C2. Ease of use}

The "Ease of Use" dimension analyzes if an app is intuitive and teachers are able to engage it with minimal guidance. This evaluation dimension has been identified repeatedly in several software evaluation rubrics (Coughlan \& Morar, 2008; Elissavet \& Economides, 2003; Kennedy et al., 1998; Lee \& Cherner, 2015; Schibeci, et al., 2008; Shiratuddin \& Landoni, 2002). This dimension is often confused with the "Navigation" dimension. Whereas the "Navigation" dimension looks at the directional structure throughout the app, the "Ease of Use" dimension examines the visual components on a single interface. For instance, this dimension assesses how easy it is for teachers to understand the visual components that appear on the screen, identify interactive buttons, make selections, and execute different tasks.

Example App for Ease of Use. Apps that use clear, thoughtful icons and visual aids to symbolize complex functions score well in this dimension. For example, ZipGrade speedily grades and processes students' multiple-choice test answers. To do so, teachers must first print test forms from the ZipGrade website and fill in the correct answers for their tests in the ZipGrade app. Students will then fill in their answer bubbles on the ZipGrade multiple choice form when completing an assessment and hand them in when finished. Using the ZipGrade app and built in tablet camera, ZipGrade automatically analyzes students' answers and adds students' grades to a digital grade book. As compared to scoring multiple-choice responses by hand or using a ScanTron system, ZipGrade scores high on this dimension due to its use of intuitive buttons and icons.

\section{C3. Customization}

The "Customization" dimension analyzes whether an app allows teachers to personalize its settings and preferences, and it connects to user experience theory (Garrett, 2010). Accordingly, visual elements such as color and typography are influential to teachers' perceptions in the psychological and affective domains. The subtle changes in color or typography can induce strong emotional reactions, such as enjoyment, excitement, fear, and anger (Shneiderman \& Plaisant, 1987). As such, allowing teachers to adjust an app's background, font typeface, or icon to their liking encourages them to interact with the app.

Example App for Customization. Apps that allow teachers to personalize them score well in this dimension, and TeacherKit demonstrates those qualities. With it, teachers can create classes and then choose from an array of display colors to represent those classes and code them by subject. In addition, teachers can upload a picture to serve as the icon for each class or subject entered into the app. TeacherKit further personalizes the experience by analyzing the class picture and identifying students' faces. The app will then assign the students' headshots to their respective academic profiles, and teachers can choose to use them as part of the app's seating chart and attendance functions. The advanced ways teachers can use this app to personalize their experience allows it to score highly in this dimension. 


\section{C4. Aesthetics}

The "Aesthetics" dimension evaluates an app's graphics and interface. This dimension analyzes the artistic aspects of an app regarding its beauty and elegance (Reeves \& Harmon, 1993). Multiple studies have examined the impacts of perceived attractiveness on human behaviors (Bloch, 1995; Ha et al., 2007; Tractinsky et al., 2000; Van der Heijden, 2003). Perceived attractiveness was found to positively related to favorable attitudes (Bloch, 1995), decision making (Van der Heijden, 2003), perceived usefulness (Tractinsky et al., 2000) and perceived enjoyment (Ha et al., 2007). More recently, in a study of web portals, Liao et al. (2011) found that the visual aspect of a website not only influences users' first impressions of the website, but it also affects their perceptions of usefulness and playfulness. Due to this finding, an app with a visually appealing interface will likely impress teachers and invite them to engage it.

Example App for Aesthetics. A high level of artistry, style, and refinement in an app's design and graphics contribute to scoring well in this category. For example, Teachers Pay Teachers includes charming graphics calling attention to holiday specials, different categories of lesson plans, and classroom activities. Many of the app's materials themselves have custom artwork that demonstrates to teachers what the materials entail. The graphics and polished aesthetics used by the app increase its perception, and those characteristics exemplify the attributes needed for an app to score well in this dimension.

\section{C5. Screen design}

The "Screen Design" dimension analyzes if an app's text, graphics, videos, sound, and speech are organized in an effective manner. Screen design had been long recognized as a crucial role for human-machine interaction (Helander et al., 2014; Olson \& Olson, 1990). An effective interface between teachers and apps can facilitate meaningful interaction, leading to a better experience for teachers. Reeves and Harmon (1993) stated that screen design is a fairly complex dimension that can be broken down into separate elements, such as text, icons, graphics, color, and other visual aspects of computer programs. However, if it is to measure each of those elements individually, the process is too trivial and complicated. In response, Lee and Cherner (2015) treated screen design holistically by considering if an app's graphics, videos, sound, text, and speech are organized in a way that enhances its screen design.

Example App for Screen Design. Apps that weave text, graphics, videos, sound, and speech into effectively organized interfaces score highest in this category. MindMeister, for example, presents media pieces that are well designed and integrated into the app. The app's text is easy to read, its colors are complimentary, the graphics - both the static interface and mind mapping manipulatives - are thoughtfully organized, and the communication messenger effectively combine multiple media elements together. MindMeister scores well in Screen Design for the way media and information are presented to enhance teachers' experience using the app.

\section{C6. Information presentation}

The "Information Presentation" dimension is concerned with teachers' ability to process and comprehend the information presented in an app. The way the information is presented has significant impact on it being comprehended. In Weinschenk's (2011) study, simply adding a title or heading was found to dramatically increase comprehension. According to Mergel (1998), breaking lengthy text into meaningful segments and then carefully organizing instructional materials that connect back to those segments leads to better comprehension. As such, apps that use clear presentation formats, so teachers can quickly engage its content in a logical manner, score well on this category. 
Example App for Information Presentation. Apps with clear formatting, contrasting headings, easily discernible fonts, and succinct segments of text score best in this dimension. An exemplar app for this category is the Classroom Ideas to Go! app due to the different text stylings used. For instance, the app uses headings to separate them from the body text, which is indicated using red coloration and bold formatting. Text used to describe different instructional elements is formatted using an italic gray style, so it is not distracting. Furthermore, the body text is efficiently broken into concise, easily readable portions. As such, the Classroom Ideas to Go! app scores highly in this because its presentation of information lets teachers quickly scan and comprehend its content.

\section{C7. Media integration}

The "Media Integration" dimension analyzes if the texts, graphics, videos, sounds, and speech used by an app are integrated effectively with one another to form a cohesive program (Reeves \& Harmon, 1993). According to multimedia learning theory, the different media elements in an electronic environment should complement one another to form a quality instructional experience (Mayer, 2001; Mayer \& Anderson, 1991, 1992). If these media elements fail to integrate with one another, it may distract teachers' attention and increase the cognitive load, resulting in a disjointed product. A high score in this dimension indicates that the media components support each other, which suggests the app is a cohesive program.

Example App for Media Integration. Apps that combine different types of media together effectively score highly in this dimension. For example, ShowMe Interactive Whiteboard helps teachers create instructional videos where they can record their own video, create their own graphics, and record their own audio, or import different media while compiling their videos. Because the app allows teachers to integrate the different media features together when producing videos and then share them easily, it demonstrates quality media integration as defined by this dimension.

\section{C8. Free of distractors}

The "Free of Distractors" dimension evaluates if an app is free of advertisements or any other distracting visual elements. These distracting components of an app are extraneous content that redirects attention away from activities to somewhere else (Mayer \& Moreno, 2003). Even when these distracting elements are not intrusive and only appear on the edge of the screen, they can still capture teachers' attention, which results in them having to spend additional mental effort to ignore them (Hong et al., 2004; Zhang, 2000). Nowadays, many free apps come with built-in advertisements. These advertisements are often in animated format and compete for attention, and their onscreen presence can be annoying and disturbing. A high score in this dimension indicates an app is free of these distracting elements.

Example App for Free of Distractors. Apps that have advertisements, popups, or banners score low on this dimension. One way developers are profiting from apps is by designing both free and paid versions. Though the paid versions score higher on this dimension because they are free of ads, the free versions score lower because the developers aim to earn revenue through advertisements and, by default, encourage the purchase of the paid version. The Splashtop Extended Wireless Display app, which offers both free and paid versions, exemplifies this strategy. The Splashtop Extended Wireless Display 2 Free app includes advertisements for its premium version, which takes away from the app's content and functionality. As a result, it scores poorly on this dimension.

\section{Recommendations for Using this Rubric}

To ensure accurate ratings when using this rubric, the following recommendations are offered to support evaluators: 
1. Be aware of an app's purpose. The design of an app will affect its score. For example, an app that was created to be a bank of lesson plans has a different purpose than an app created to be a classroom management tool. When assessing an app, understanding its purpose will help the evaluators ensure why an app includes specific features and how those features can be used.

2. Understand the rubric and its dimensions. Though this rubric is based on previously conducted research and scholarship related to instructional technologies, evaluators will still need time to practice using this rubric for assessing apps. As the evaluators gain practice using this rubric, their efficacy for assessing apps will increase. In turn, the accuracy of their evaluations will improve.

3. Develop an understanding of an app before evaluating it. As apps grow increasingly sophisticated and complex, evaluators need time to work through the different tools, features, and functionalities that an app may have. By taking the time to fully examine an app, it will increase the accuracy of the evaluation and ensure a thorough analysis was conducted.

4. Consider how an app can be used by teachers. When assessing an app, evaluators need to view it from a teacher's perspective. Though other lenses have value (e.g., instructional coach, administrator, and app developer), this rubric was designed specifically to analyze how an app can be used by a teacher. Therefore, to help ensure the validity of an app evaluation using this rubric, it needs to be assessed from a teacher's perspective.

By understanding these recommendations for evaluating teacher resource apps, the quality of the analysis using this rubric is enhanced. To help readers conceptualize how to assess apps using this rubric, a narrative of how the rubric can be used to evaluate an app is offered next.

Edmodo is an app designed to be a digital classroom and learning community. With it, teachers are able to create classes that students can join. After creating a class, teachers are able to post comments, assignments, polls, and assessments to the "wall" that students can respond to and/or complete. In addition, Edmodo includes a built-in grade book feature, document saving system, and assessment analytics tool. Because Edmodo is modeled after popular social media platforms, teachers are able to find and connect with or follow other teachers and communities. Packaged together, Edmodo is intended to be a premier educational app for teachers. After evaluators have spent time with Edmodo and explored its different functionalities, the researchers suggest they

Table 3: Edmodo Evaluation

DOMAIN A: EFFICIENCY

A1. Productivity: 5

A2. Frequency: 5

A3. Guidance: 5

A4. Relevance: 5

A5. Credibility: 3

A6. Differentiation: 5

\section{DOMAIN B: FUNCTIONALITY}

B1. Multipurpose: 5

B2. Collaboration \& Communication: 4

B3. Ability to Save Progress: 4

B4. Modification: 4

B5. Platform Integration: 4

B6. Security: 3

\section{DOMAIN C: DESIC}

C1. Navigation: 4

C2. Ease of Use: 4

C3. Customization: 5

C4. Aesthetics: 5

C5. Screen Design: 5

C6. Information Presentatior

C7. Media Integration: 5

C8. Free of Distractors: 5 
assess it using the indicators in domain A before progressing to domains $\mathrm{B}$ and $\mathrm{C}$. The reason for this suggestion is that Domain A is intended for evaluators to understand how the app will benefit teachers directly in completing common, daily tasks before they assess it using Domain B's indicators, which analyze tools the app includes to support how teachers can effectively use the app. Finally, Domain $\mathrm{C}$ culminates the evaluation by analyzing the quality of the app's design. The researchers designed the rubric with this progression in mind in order to give a logical "flow" to the evaluation process. Table 3 offers scores for Edmodo based on the rubric.

\section{Limitations}

Though care was used when crafting and developing this rubric, it is not free of limitations. As used in this article, the researchers define limitations as factors that potentially inhibit or reduce the accuracy of an app's score using this evaluation rubric (Given, 2008), and the following discussion points are limitations that the researchers identified.

First, technology is continually evolving. As such, new advances in the field of educational apps will likely occur. As they do, future researchers will need to modify and revise this rubric to ensure it continues to be a meaningful tool for evaluating teacher resource apps.

Second, this rubric was designed specifically for teacher resource apps. As Lee and Cherner (2015) explained, "creating a single rubric to evaluate all varieties of educational apps is not possible" (p. 37). Therefore, because they already created a comprehensive rubric for instructional apps, there was a need to design one for teacher resource apps. A concern is that a teacher resource app could be mistakenly evaluated using the rubric for assessing instructional apps and vice versa. This situation warrants a limitation for the two rubrics.

Third, the true value of an educational app of any kind cannot be limited to a quantitative evaluation. Rather, it is and always will be the way teachers use resources of all kinds in their classroom. Regardless if the resource is a book, app, or other manipulable, there is value if teachers are able to use them to engage students and promote learning.

Fourth, this rubric was designed to analyze different characteristics of an app; it was not meant to provide a holistic score for an entire app. The domains and dimensions used in the rubric identify different characteristics of quality apps, and it is unlikely for an app to earn top scores in all the areas. Teachers and evaluators would be wise to consider the purpose(s) they have for the app and then analyze the app for those purposes.

\section{Implications for Future Research and Practice}

The purpose of this article was to create and present a peer-reviewed rubric for researchers and practitioners to use when evaluating the quality of teacher resource apps. With the goal of increasing the quality of teacher resource apps being produced by developers, additional research that uses this rubric needs to be conducted. For example, future researchers could systematically collect a representative sampling of teacher resource apps and categorize them by purpose. Example categories are Assessment, Classroom Management, Grade Book and Attendance, Instructional Tools, and Lesson Planning. Researchers could then rate the apps in different categories using this rubric and examine their ratings for any trends that they identify in the data. Researchers could then explain those trends and make recommendations for ways developers could improve the quality of the apps they are producing based on the study's findings.

A second study could analyze the quality of app recommendations made by different online resources based on this rubric. Teachers often use different websites - blogs, social media, website databases, wikis - to learn about educational apps they can use in the classroom. However, the quality of the recommendations made by these websites goes unanalyzed, though a website may 
have several thousand visitors monthly. To study these websites, researchers could rate the teacher resource apps recommended by them using the rubric. After multiple websites were reviewed, researchers could rank them based on their findings, analyze trends in the collected data, and make suggestions for the criteria websites should consider when making app recommendations. One provocative line of study is to analyze if blogs, social media, website databases, or wikis recommend the highest quality apps, and that study would have direct benefits for practitioners.

Practitioners are at the forefront of using instructional technologies on a regular basis. Whether the practitioner is a classroom teacher, instructional coach, teacher educator, or technology specialist, all these individuals would benefit by using this rubric when selecting teacher resource apps. As referred to in the second proposed study, the websites practitioners turn to when learning about new instructional strategies are unregulated. There is no "accreditation" or "peer-review process" in place for these internet-based resources. Rather, popularity is determined by strategic keywords aligned to search engine optimization, not best practices or use of research. The rubric presented in this article is a tool practitioners can use to independently analyze teacher resource apps and then make decisions based on their own analysis. Similar to how teachers use action research to improve their classroom instruction (Levin \& Merritt, 2006; Mertler, 2009), this rubric can be used by practitioners to knowingly select apps based on their quality. In both instances, practitioners are empowered because they are the ones conducting the testing and analysis to improve their craft and practice.

In its current form, there is no standard for which characteristics are inherent in a quality teacher resource app specifically, or educational app in general. App developers are rarely educators, and, though they may be well able to create an educational app, the way practitioners use their app may be very different from how they envisioned it when designing, testing, and developing it. In effect, this rubric puts forward specific, research-based qualities developers can include in the teacher resource apps they create. The first recommended study may result in specific trends found in teacher resource apps, and developers can use that research to inform the future apps they will create. The second study is intended to analyze the internet-based resources themselves that recommend educational apps. Websites that recommend apps must have specific criteria for which to base their recommendations, and a cursory review of those websites reveals, at best, that an inconsistency in criteria exists and, at worst, no criteria is used. The final point is that practitioners can use this rubric to empower themselves when selecting teacher resource apps, so they do not have to rely on outside, third parties.

\section{Conclusion}

As iPads and other mobile devices have been in schools for over five years (Banister, 2010; Melhuish \& Falloon, 2010; Meurant, 2010), teacher resource apps represent an area that has not yet been studied. In fact, based on the literature review that was conducted as part of this article, there has been relatively no work completed to assess the quality of apps designed specifically for teachers. This gap in the research represents an area that can be developed, so teachers have a research base for selecting apps that will support them in completing their routine tasks. As such, the purpose of this article and its accompanying rubric was to identify the attributes of teacher resource apps and distinguish the criteria that separate quality and inferior apps. Practitioners, in turn, can then use this rubric to inform both their selection of teacher resource apps and the websites they consult when selecting them. With the booming educational app market, new teacher resource apps are being continually developed and released. The rubric put forward in this article is intended to help establish a set of characteristics that contribute to teacher resource apps being effective and valuable for practitioners. 


\section{References}

Balefire Labs. (2013). Browse apps reviews. Retrieved from http://www.balefirelabs.com/apps/tag/ios/

Banister, S. (2010). Integrating the iPod Touch in K-12 education: Visions and vices. Computers in the Schools, 27(2), 121-131.

Barseghian, T. (2011). 21 things that will be obsolete by 2020. Mind/Shift. Retrieved from http://ww2.kqed.org/mindshift/2011/03/02/21-things-that-will-be-obsolete-by-2020/

Bloch, P. H. (1995). Seeking the ideal form: Product design and consumer response. The Journal of Marketing, 59(3), 16-29.

Bouard, A., Schanda, J., Herrscher, D., \& Eckert, C. (2013). Automotive proxy-based security architecture for device integration. In C. Borcea, P. Bellavista, C. Gianelli, T. Magedanz, \& F. Schreiner (Eds.), Mobilware 2012, Vol. 65, (pp. 62-76). Heidelberg, Germany: Springer.

Buckler, T. (2012). Is there an app for that? Developing an evaluation rubric for apps for use with adults with special needs. The Journal of BSN Honors Research, 5(1), 19-32.

Carlson, J. A. (2010). Avoiding traps in member checking. The Qualitative Report, 15(5), 1102-1113.

Cherner, T., Dix, J., \& Lee, C. (2014). Cleaning up that mess: A framework for classifying educational apps. Contemporary Issues in Technology and Teacher Education, 14(2). Retrieved from http://www.citejournal.org/vol14/iss2/general/article1.cfm

Coffey, A., \& Atkinson, P. (1996). Making sense of qualitative data: Complementary research strategies. Thousand Oaks, CA: Sage.

Coughlan, J., \& Morar, S. S. (2008). Development of a tool for evaluating multimedia for surgical education. Journal of Surgical Research, 149(1), 94-100.

Elissavet, G., \& Economides, A. A. (2003). An evaluation instrument for hypermedia courseware. Educational Technology \& Society, 6(2), 31-44.

Garrett, J. J. (2010). Elements of user experience: The user-centered design for the web and beyond (2nd ed.). Berkeley, CA: Pearson Education.

Given, L. (2008). The SAGE encyclopedia of qualitative research methods. Thousand Oaks, CA: Sage.

Ha, I., Yoon, Y., \& Choi, M. (2007). Determinants of adoption of mobile games under mobile broadband wireless access environment. Information \& Management, 44(3), 276-286.

Heide, A., \& Henderson, D. (2001). Active learning in the digital age classroom. Portsmouth, NH: Heinemann.

Helander, M. G., Landauer, T. K., \& Prabhu, P. V. (Eds.). (2014). Handbook of human-computer interaction. New York, NY: Elsevier Science Publishers.

Hofstein, J. D., Tucker, L., Swarner, K., Moriarty, D., Tegas, L., DeMarte, N., \& Adiletta, N. (2013). Using iPads in the chemistry classroom: Focusing on paperless education and identification and directed use of pedagogically directed applications. The Chemical Educator, 18, 248-254.

Hong, W., Thong, J. Y., \& Tam, K. Y. (2004). Does animation attract online users' attention? The effects of flash on information search performance and perceptions. Information Systems Research, 15(1), 6086.

Hsu, Y-C., Ching, Y-H., \& Grabowski, B. L. (2014). Web 2.0 applications, practices, and learning through collaboration. In M. Spector, D. Merrill, J. Elen, \& M. J. Bishop (Eds.), Handbook of research on educational communications and technology (4th ed.), (pp. 747-758). New York, NY: Springer.

Hu, W. (2009, September 17). Fewer fliers sent home as schools put more on web. The New York Times. Retrieved from http://www.nytimes.com/2009/09/08/education/08mail.html?_r=0

Jamieson, S. (2004). Likert scales: How to (ab)use them. Medical Education, 38, 1217-1218. 
Jiang, H., Ma, H., Ren, Z., Zhang, J., \& Li, X. (2014). What makes a good app description? In H. Mei \& J. Lv, Proceedings of the 6th Asia-Pacific Symposium on Internetware on Internetware. (pp. 45-53). New York, NY: ACM Digital Publishing.

Kameenui, E. J., \& Carnine, D. W. (1998). Effective teaching strategies that accommodate diverse learners. Des Moines, IA: Prentice Hall.

Kennedy, G., Petrovic, T., \& Keppell, M. (1998). The development of multimedia evaluation criteria and a program of evaluation for computer aided learning. ASCILITE, 98, 407-415.

Krefting, L. (1991). Rigor in qualitative research: The assessment of trustworthiness. American Journal of Occupational Therapy, 45(3), 214-222.

Lee, C-Y., \& Cherner, T. S. (2015). A comprehensive evaluation rubric for assessing instructional apps. Journal of Information Technology Education: Research, 14, 21-53. Retrieved from http://www.jite.org/documents/Vol14/JITEV14ResearchP021-053Yuan0700.pdf

Levin, B. B., \& Merritt, S. P. (2006). Guest editors' introduction: Actin research for teacher empowerment and transformation. Teacher Education Quarterly, 33(3), 3-6.

Liao, C., To, P. L., Liu, C. C., Kuo, P. Y., \& Chuang, S. H. (2011). Factors influencing the intended use of web portals. Online Information Review, 35(2), 237-254.

Litayem, N., Dhupia, B., \& Rubab, S. (2015). Review of cross-platforms for mobile learning application development. IJACSA) International Journal of Advanced Computer Science and Applications, 6(1). 31-39.

Mayer, R. E. (2001). Multi-media learning. Cambridge, UK: Cambridge University Press.

Mayer, R. E., \& Anderson, R. B. (1991). Animations need narrations: An experimental test of a dualcoding hypothesis. Journal of Educational Psychology, 83(4), 484-490.

Mayer, R. E., \& Anderson, R. B. (1992). The instructive animation: Helping students build connections between words and pictures in multimedia learning. Journal of Educational Psychology, 84(4), 444452 .

Mayer, R. E., \& Moreno, R. (2003). Nine ways to reduce cognitive load in multimedia learning. Educational Psychologist, 38(1), 43-52.

McIlroy, S., Ali, N., Khalid, H., \& Hassan, A. E. (2015). Analyzing and automatically labelling the types of user issues that are raised in mobile app reviews. Empirical Software Engineering, 21(3), 1067-1106.

Melhuish, K. \& Falloon, G. (2010). Looking to the future: m-learning with the iPad. Computers in New Zealand Schools: Learning, Leading, Technology, 22(3), 1-16.

Mertler, C. A. (2009). Action research: Teachers as researchers in the classroom (2nd ed.). Los Angeles, CA: Sage.

Mergel, B. (1998). Instructional design and learning theory. Retrieved from http://etad.usask.ca/802papers/mergel/brenda.htm

Meurant, R. (2010). The iPad and EFL digital literacy. Communications in Computer and Information Science, $123,224-234$.

Morgan, H. (2014). iPad programs could lead to a bright future for schools. New Horizons for Learning, 11(1), 1-5.

Olson, J. R., \& Olson, G. M. (1990). The growth of cognitive modeling in human-computer interaction since GOMS. Human-Computer Interaction, 5(2-3), 221-265.

Parsons, A. (n.d.). Student app quality guidelines. Dreamspark. Retrieved from https://www.dreamspark.com/Student/Student $\% 20 \mathrm{App} \% 20$ Quality $\% 20 \mathrm{v} 1 \% 200 . \mathrm{pdf}$ 
Reeves, T. C., \& Harmon, S. W. (1993). Systematic evaluation procedures for interactive multimedia for education and training. In S. Reisman (Ed.), Multimedia computing: Preparing for the 21st century (pp. 472-505). Harrisburg, PA: Idea Group Publishing.

Richardson, J. W., McLeod, S., Flora, K., Sauers, J., Kannan, S., \& Sincar, M. (2013). Large-scale 1:1 computing initiatives: An open access database. International Journal of Education and Development Using Information and Communication Technology, 9(1), 4-18.

Schibeci, R., Lake, D., Phillips, R., Lowe, K., Cummings, R., \& Miller, E. (2008). Evaluating the use of learning objects in Australian and New Zealand schools. Computers \& Education, 50(1), 271-283.

Shiratuddin, N., \& Landoni, M. (2002). Evaluation of content activities in children's educational software. Evaluation and Program Planning, 25(2), 175-182.

Shneiderman, B., \& Plaisant, C. (1987). Designing the user interface: Strategies for effective humancomputer interaction. Reading, MA: Addison-Wesley Publishing Company.

Tomlinson, C. (1999). The differentiated classroom: Responding to the needs of all learners. Alexandria, VA: Association for Supervision and Curriculum Development.

Tractinsky, N., Katz, A. S., \& Ikar, D. (2000). What is beautiful is usable. Interacting with Computers, $13(2), 127-145$.

Van der Heijden, H. (2003). Factors influencing the usage of websites: The case of a generic portal in the Netherlands. Information \& Management, 40(6), 541-549.

Walker, H. (2011). Evaluating the effectiveness of apps for mobile devices. Journal of Special Education Technology, 26(4), 59-63.

Wasniewski, E. (2013). One-on-one with an iPad: A faculty perspective on iPad supports for students with disabilities. In R. McBride \& M. Searson (Eds.), 2013 Society for Information Technology \& Teacher Education International Conference (pp. 4346-4351). Chesapeake, VA: LearnTechLib.

Weinschenk, S. (2011). 100 things every designer needs to know about people. Berkeley, California: New Riders.

Zhang, P. (2000). The effects of animation on information seeking performance on the World Wide Web: Securing attention or interfering with primary tasks? Journal of the AIS, 1, 1-28.

Zhu, H., Xiong, H., Ge, Y., \& Chen, E. (2014, August). Mobile app recommendations with security and privacy awareness. In S. Mackassy, \& C. Perlich, Proceedings of the 20th ACM SIGKDD International Conference on Knowledge Discovery and Data Mining, Sheraton New York Times Square Hotel (pp. 951-960). New York, NY: ACM. 


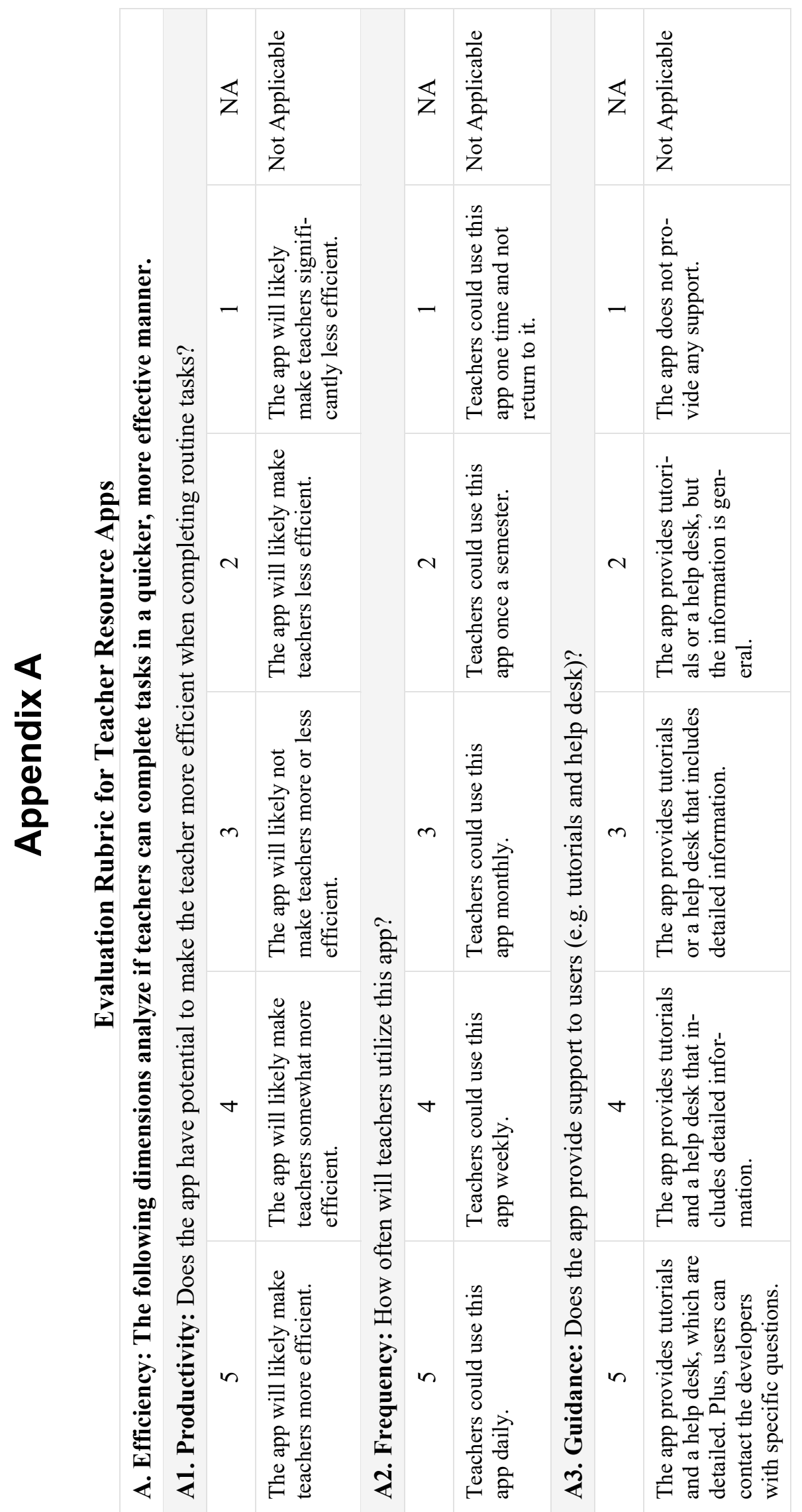




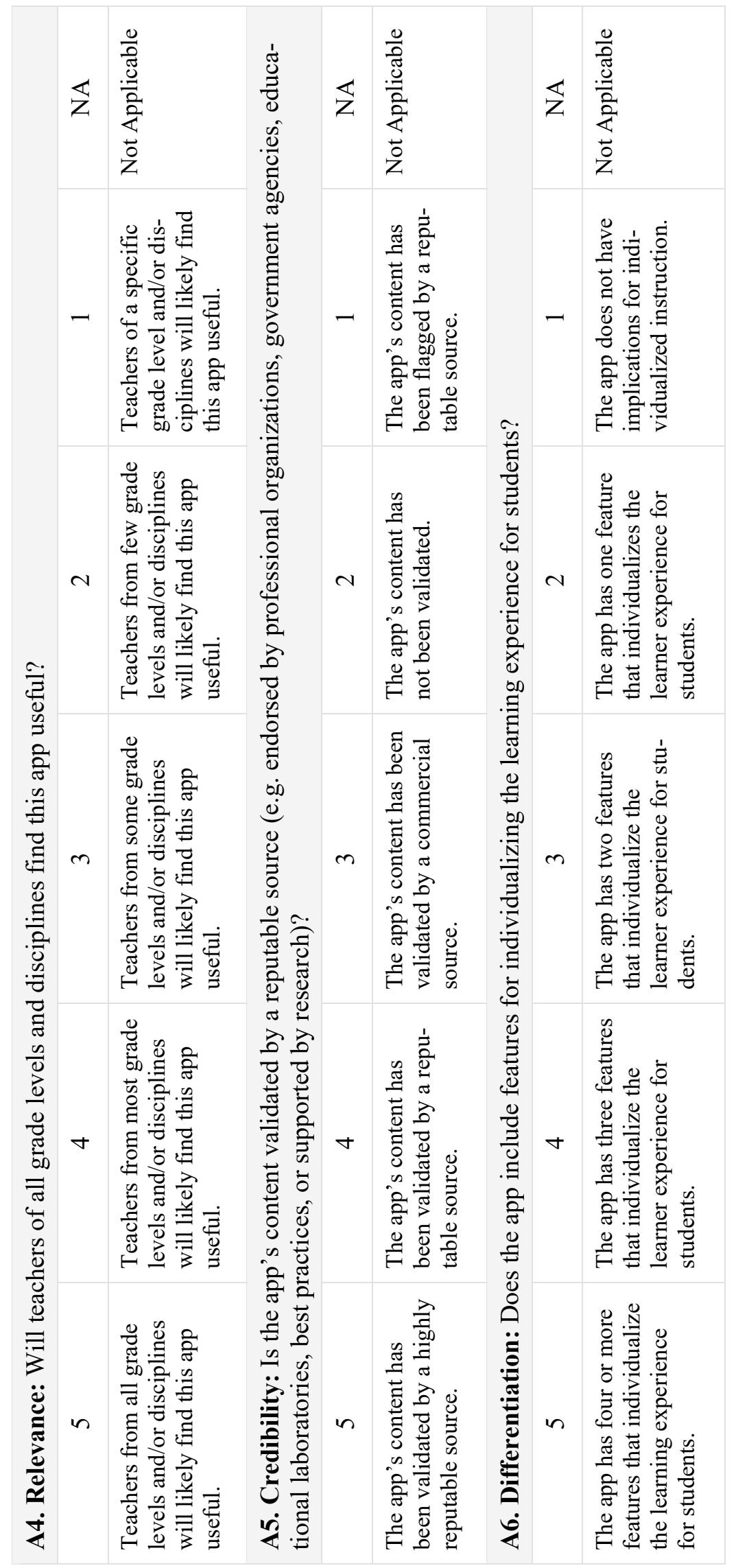




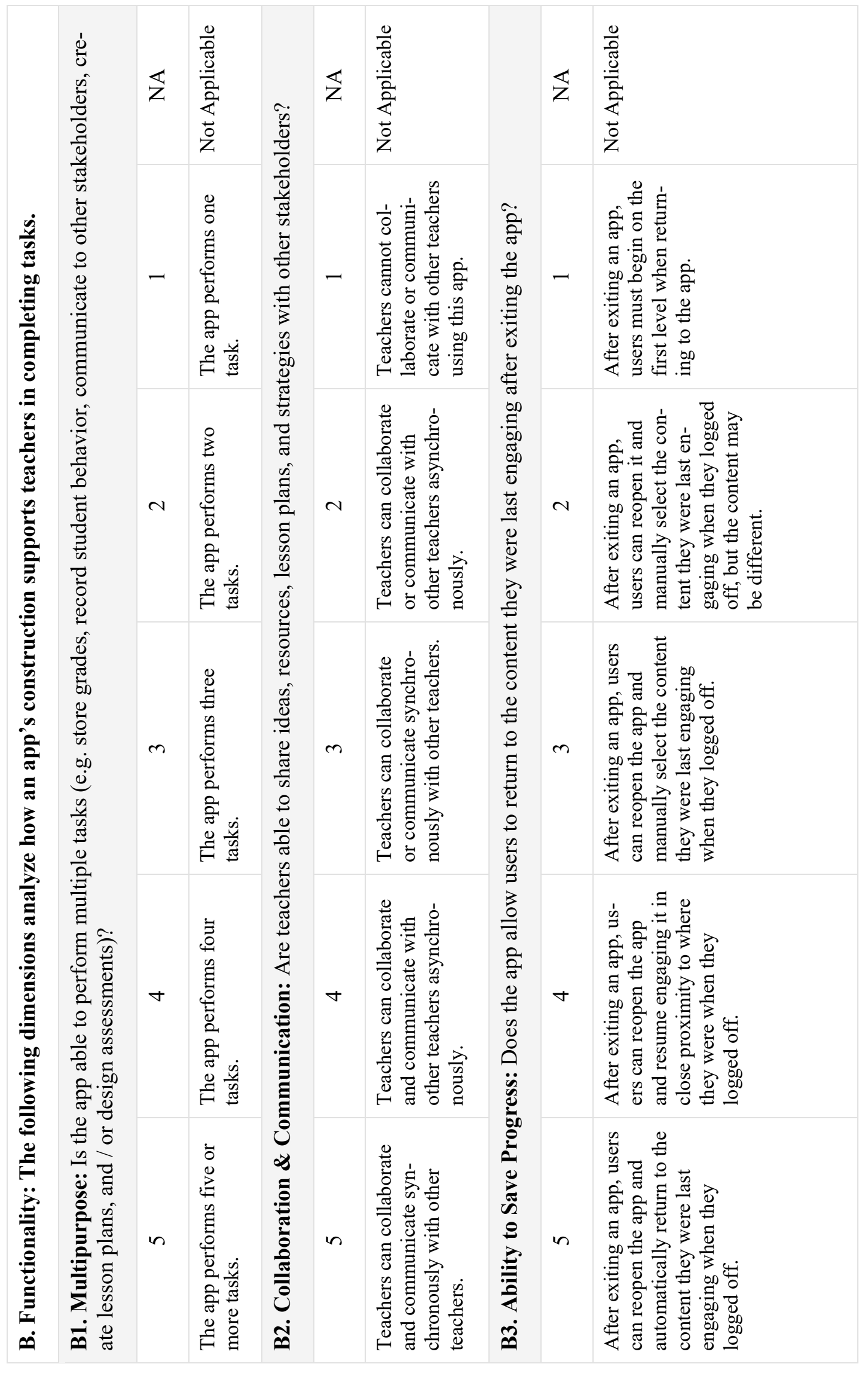




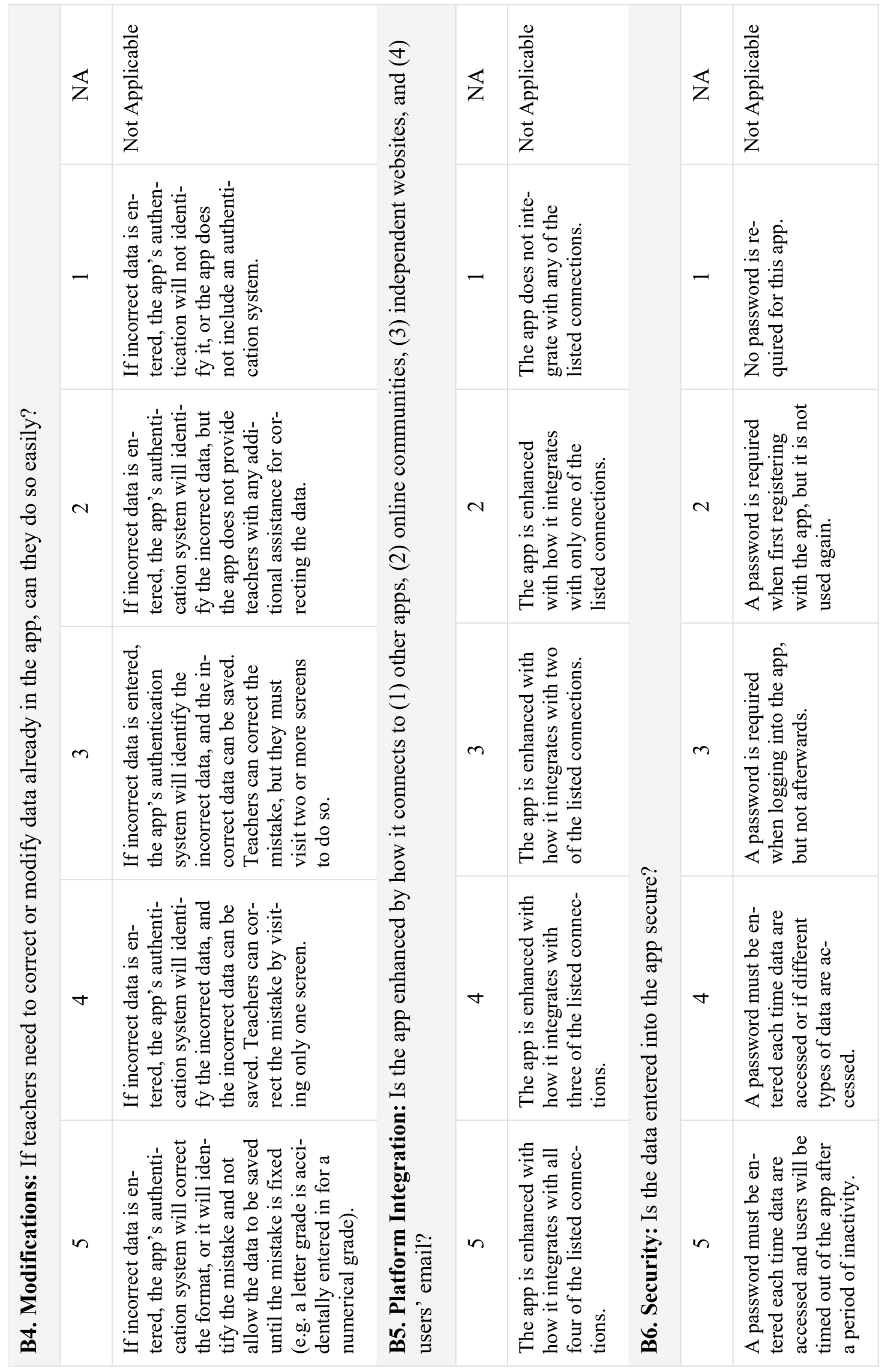




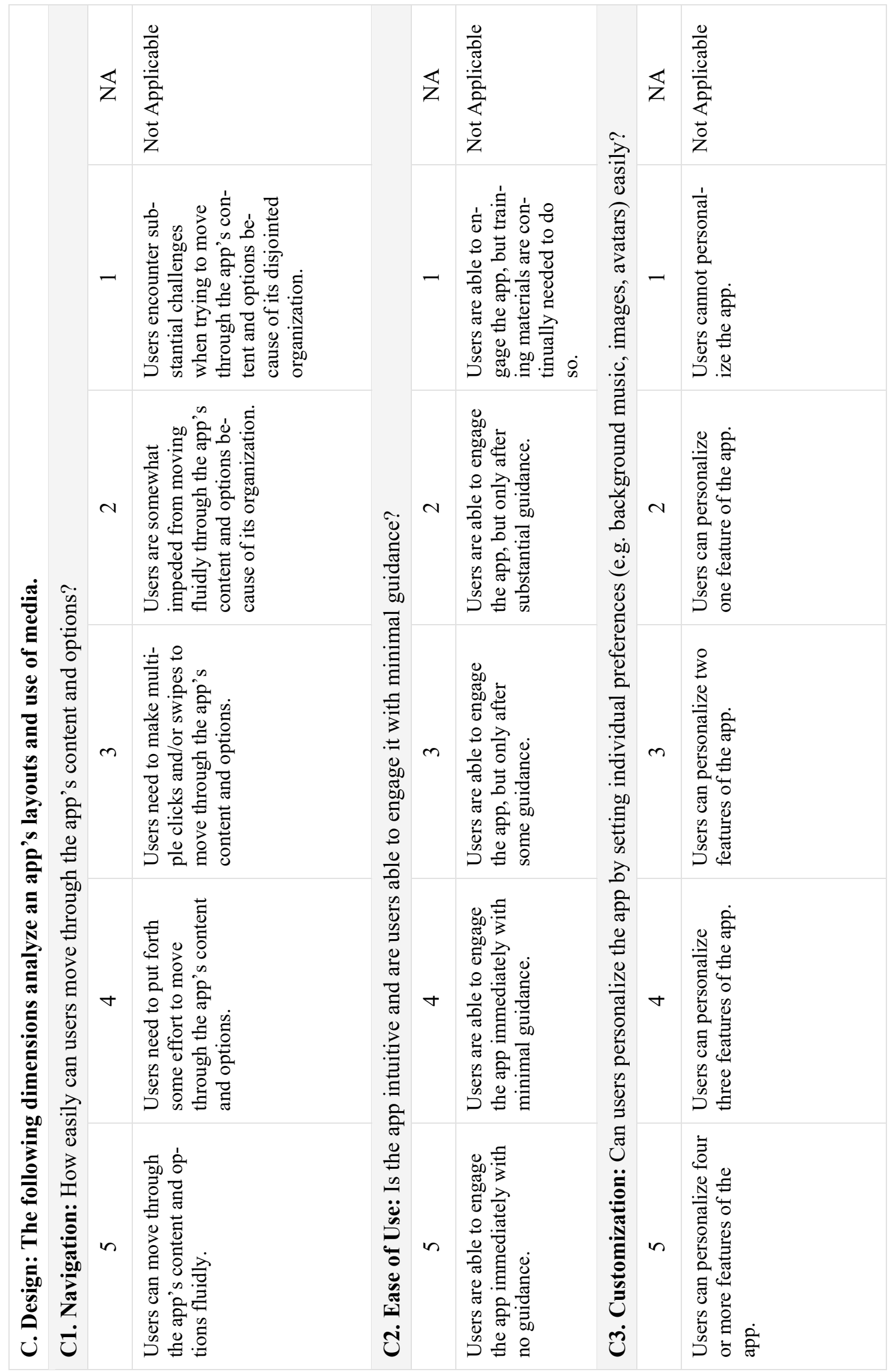




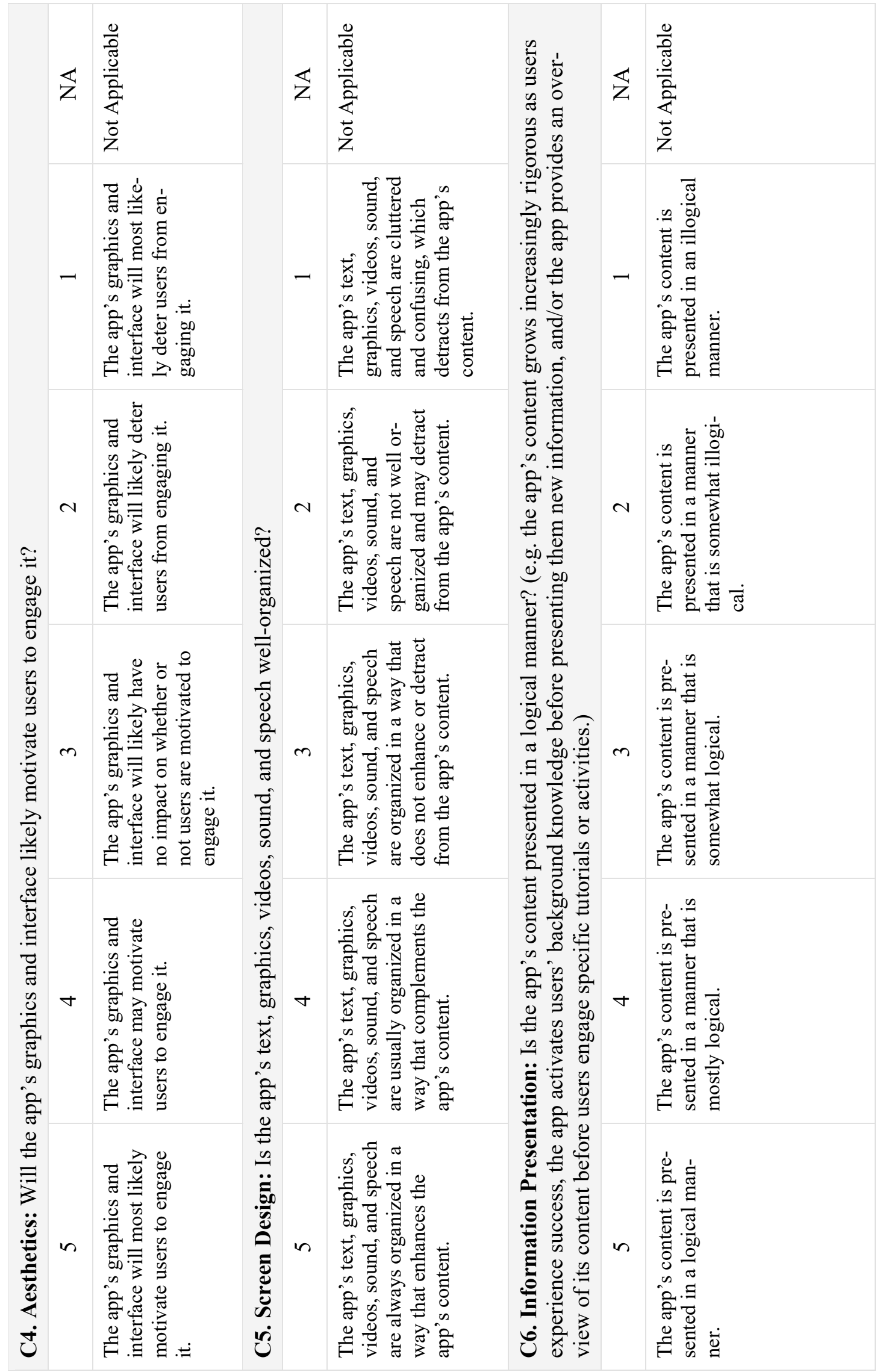




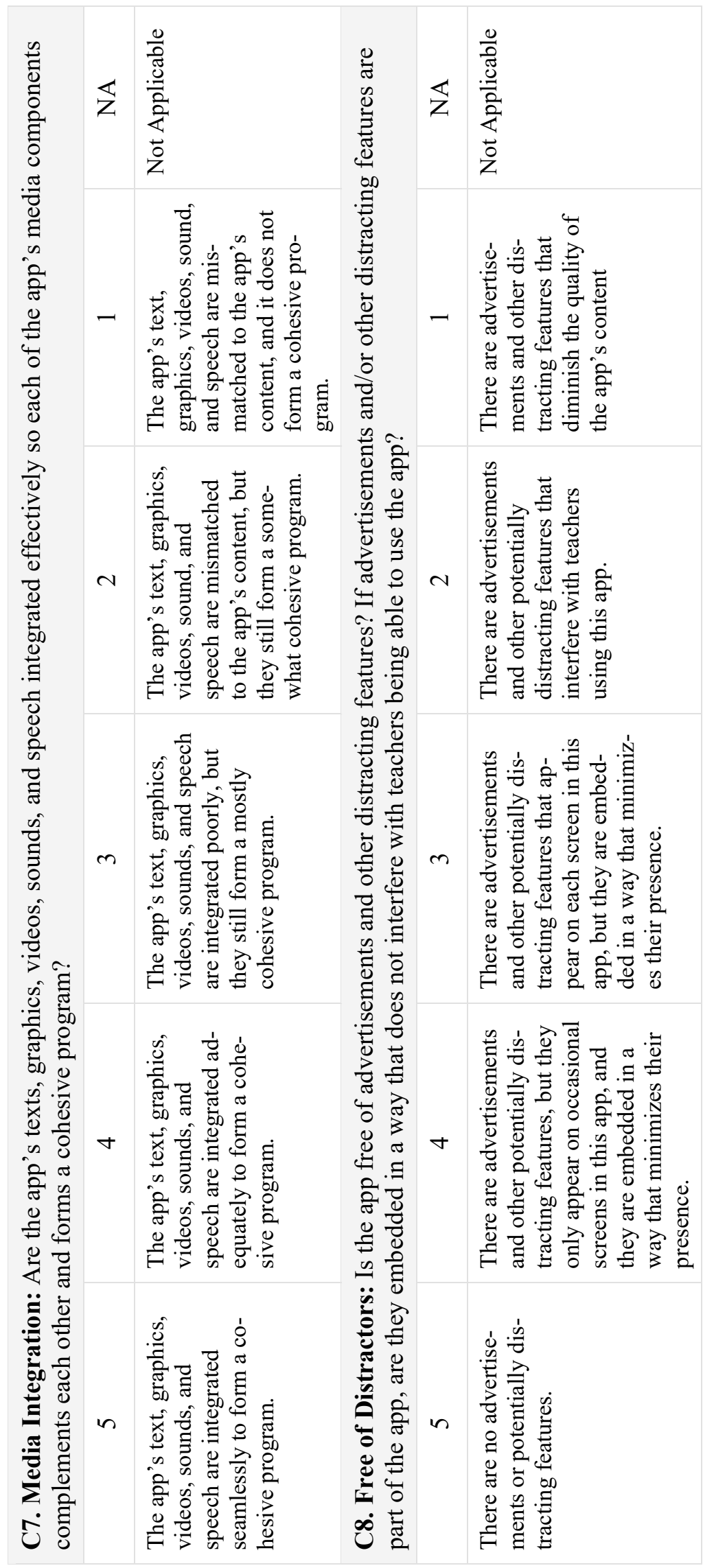




\section{Appendix B}

\section{Validation of the Evaluation Rubric for Tablet Apps}

Thank you for your willingness to critique our instrument. Your feedback will provide us with information about how we can better refine our instrument, and please provide your feedback using the following form.

Name: Title:

Number of years that you have been an educator:

\section{Your field of expertise:}

Directions: Please review each of the following dimensions to determine how "concise" and "adequate" they are by rating them on a 5-point scale using the following breakdown:

$$
\mathbf{5}=\text { Very Good } \quad \mathbf{4}=\text { Good } \quad \mathbf{3}=\text { Average } \quad \mathbf{2}=\text { Below Average } \quad \mathbf{1}=\text { Poor }
$$

Additionally, the "concise" rating focuses on how succinct and crisp the language used to describe the dimension is. The "adequate" rating determines if the language used satisfactorily describes the dimension's focus. Lastly, please provide any additional comments in the space following each dimension, especially if a rating of 1,2 , or 3 is assigned.

How concise is this dimension's question?

How adequate is this dimension's question?

How concise are this dimension's indicators?

How adequate are this dimension's indicators?

$\begin{array}{lllll}5 & 4 & 3 & 2 & 1\end{array}$

Additional Comment(s) and Suggestion(s):

$\begin{array}{lllll}5 & 4 & 3 & 2 & 1\end{array}$

$\begin{array}{lllll}5 & 4 & 3 & 2 & 1\end{array}$

$\begin{array}{lllll}5 & 4 & 3 & 2 & 1\end{array}$




\section{Biographies}

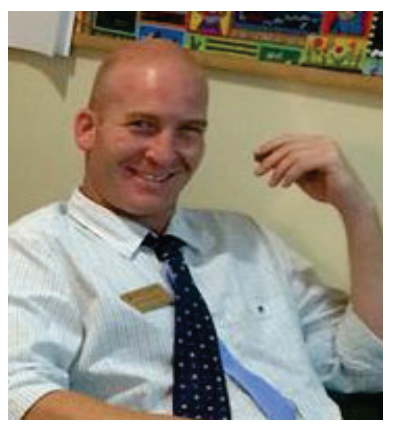

Todd Cherner is an assistant of professor of education at Portland State University. The two tenets that guide Todd's teaching and research are the following: (1) It is essential to continually develop students' literacy and technology skills throughout their compulsory education, and (2) A person who completes his/her compulsory education should be prepared for active citizenry. Through his teaching and research, Todd works to prepare in-service and pre-service teachers with the skills, innovation, and experience to provide those types of educational opportunities to their students. For his education, Todd earned his Ph.D. from the University of Tennessee, M.Ed. from Clemson University, B.S. from the University of Central Florida, and graduated Lake Mary High School.

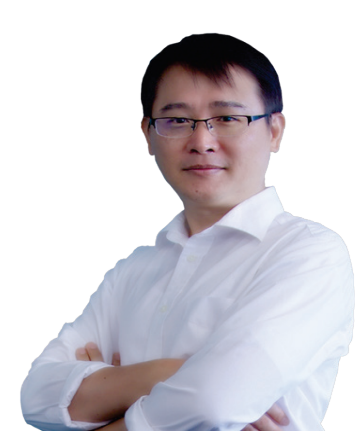

Cheng-Yuan "Corey" Lee earned a Ph.D. in curriculum and instruction with an emphasis on instructional system design from the University of Central Florida. Throughout his career of teaching, he developed strong interests in the areas of distance education, mobile learning, interactive multimedia, and graphic/website design. In his classes, he introduces a wide range of software application and open-source packages to students, allowing them to master computer-based tools used in the design and creation of electronic media, such as electronic images, sounds, videos, text, and motion.

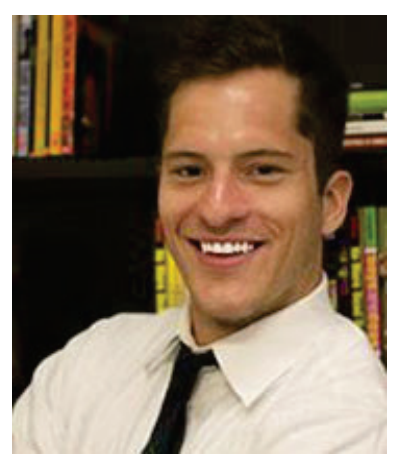

Alex Fegely is a Lecturer and Instructional Technology Specialist at Coastal Carolina University. Previously, he taught social studies, digital media, and English. Currently, his focus is on infusing STEM education and tablet technology with the arts. He believes that technology is an invaluable classroom tool for differentiating instruction and engaging learners.

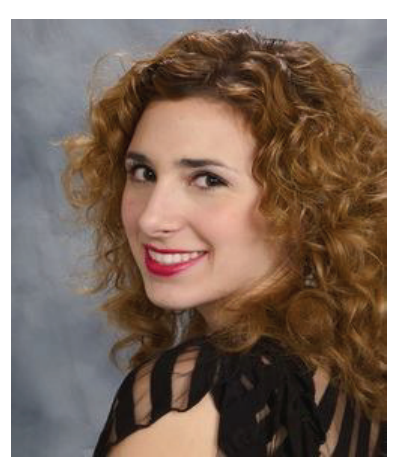

Lauren Santaniello is an English teacher at Indian Hills High School in New Jersey. She holds a teaching certificate in Literature and Secondary Education, as well as an M.Ed. in Literacy. She also holds certificates as a Reading Teacher, a Literacy Coach, and as a Teacher of Students with Disabilities. Santaniello is the author of a young adult series titled Death of Ignorance published by Stories to Tale. In the 2016-2017 school year, Santaniello will be moving from the general education classroom to a special education classroom. 